Revista Universo Contábil, ISSN 1809-3337

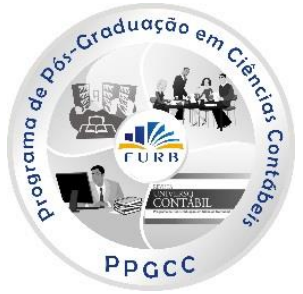

PRÁTICA VERSUS INCERTEZA: COMO GERENCIAR O ESTUDANTE NESSA TENSÃO NA IMPLEMENTAÇÃO DE DISCIPLINA SOB O PRISMA DO MÉTODO PBL? 1

\title{
PRACTICE VERSUS UNCERTAINTY: HOW TO MANAGE STUDENT THIS TENSION IN IMPLEMENTING DISCIPLINE THROUGH THE PRISM OF THE PBL METHOD?
}

\section{PRACTICA FRENTE A LA INCERTIDUMBRE: CÓMO MANEJAR ESTA TENSIÓN ESTUDIANTE EN LA APLICACIÓN DE LA DISCIPLINA A TRAVÉS DEL PRISMA DEL MÉTODO PBL?}

\author{
Fábio Frezatti \\ Doutor em Controladoria e Contabilidade pela FEA/USP \\ Professor do Departamento de Contabilidade e Atuária da FEA/USP \\ Endereço: Av. Prof. Luciano Gualberto, 908 - FEA 3 - Sala 232 - Butantã \\ CEP: 05508-900 - São Paulo - SP \\ E-mail: frezatti@usp.br \\ Telefone: (11) 3091-5820
}

Sidnei Celerino da Silva Doutorando em Controladoria e Contabilidade pela FEA/USP Professor do Colegiado de Ciências Contábeis da UNIOESTE Endereço: Rua da Bandeira, 836 CEP: 85812-270 - Cascavel - PR E-mail: sidneicelerino@yahoo.com.br Telefone: (44) 9983-7613

\section{RESUMO}

O objetivo deste trabalho é discutir, dentro das perspectivas do método problem based learning (PBL), estratégias para manter o interesse dos estudantes perante a disciplina, face à prática versus incerteza. Oferecer uma disciplina baseada no PBL em instituição de ensino superior voltada a cursos ligados a negócios, onde não seja obrigatório, é um diferencial relevante. Por outro lado, se o estudante se mostra interessado em trabalhar em um ambiente de alta praticidade, percebe que essa praticidade implica em risco não mensurável a priori e requer muito trabalho. A concorrência com atividades de outras disciplinas faz com que, além do interesse, a adequação do tempo e o constante "instigar e suportar" sejam exercidos. Como

1 Artigo recebido em 30.01.2013. Revisado por pares em 10.12.2013. Reformulado em 28.02.2014. Recomendado para publicação em 27.03.2014 por Carlos Eduardo Facin Lavarda. Publicado em 31.03.2014. Organização responsável pelo periódico: FURB. 
conclusões pela experiência vivenciada, pode-se indicar que alguns dos elementos mais importantes no processo são: (i) o leilão de problemas, (ii) o critério de definição do líder, (iii) o processo de "alocação" de participantes, (iv) expansão e redução no tratamento do problema, (v) escolha da empresa pela acessibilidade aos dados, (vi) clareza das normas de formatação e estrutura do projeto e relatório final, (vii) formas de acesso e estímulo a literatura, (viii) aulas expositivas para direcionamento e reforço das atividades, (ix) check-list das atividades das sessões tutoriais e (x) feedback das socializações, autoavaliação do processo e de aprendizagem. Esses ingredientes-chave para o sucesso na disciplina devem ser definidos a priori e gerenciados durante o curso.

Palavras-chave: Problem based learning; Implementação de disciplina; Prática; Incerteza.

\section{ABSTRACT}

The objective of this paper is to discuss, within the perspectives of the method problem based learning (PBL), strategies to maintain students' interest towards the subject in the face of uncertainty versus practice. Offer a discipline based on PBL in higher education institution focused on business-related courses, where it is not mandatory is a relevant differential. On the other hand, if the student shows interested in working in an environment of high practicality, convenience realizes that unmeasured risk implies a priori and requires a lot of work. The competition activities with other disciplines causes, besides the interest, the adequacy of time and constant "instigate and support" are exercised. As experienced conclusions by experience, may indicate that some of the most important elements in the process are: (i) the auction problems, (ii) the criterion for defining the leader, (iii) the process of "allocation" of participants, (iv) expansion and reduction in the treatment of the problem, (v) the choice of company data accessibility, (vi) clear rules for formatting and structure of the project and final report, (vii) forms of access and encouragement to literature, (viii) classes for targeting and strengthening activities, (ix) checklist activities of tutorial sessions and (x) feedback of socialization, self-assessment and learning process. These key ingredients for success in the discipline should be defined a priori and managed during the course.

Keywords: Problem based learning; Implementation of discipline; Practice; Uncertainty.

\section{RESUMEN}

El objetivo de este trabajo es discutir, dentro de las perspectivas del método de aprendizaje basado en problema (PBL), las estrategias para mantener el interés de los estudiantes hacia el tema en un contexto de incertidumbre frente a la práctica. Dar una disciplina basada en el PBL en la institución de educación superior centrado en cursos relacionados con la empresa, donde no es obligatorio es un diferencial relevante. Por otro lado, si el alumno muestra interés en trabajar en un ambiente de alta practicidad, conveniencia se da cuenta de que el riesgo no medida implica a priori y requiere mucho trabajo. Las actividades de la competencia con las causas de otras disciplinas, además de los intereses, la adecuación de tiempo y constante "instigar y apoyar" se ejercen. Como conclusiones experimentados por la experiencia, puede indicar que algunos de los elementos más importantes en el proceso son: (i) los problemas de subastas, (ii) el criterio para definir el líder, (iii) el proceso de "asignación" de los participantes, (iv) la ampliación y la reducción en el tratamiento del problema, (v) la elección de la compañía de acceso a los datos, (vi) normas claras para el formato y la estructura del proyecto y el informe final, (vii) las formas de acceso y el estímulo a la literatura, (viii) clases para la orientación y fortalecimiento de las actividades, (ix) actividades de la lista de verificación de las sesiones de tutoría y (x) la retroalimentación de la socialización, la autoevaluación y el proceso de 
aprendizaje. Estos ingredientes clave para el éxito en la disciplina debe ser definido a priori y administrado durante el curso.

Palabras clave: aprendizaje basado en problemas, la aplicación de la disciplina, la práctica, la incertidumbre.

\section{INTRODUÇÃO}

O interesse pelo problem based learning (PBL) nasceu da percepção de que a visão prática do curso deve levar em conta aspectos como solução de problemas reais do cotidiano do grupo de estudantes e que os recursos e esforços despendidos sejam dosados em função da análise, discussão e resolução desse problema. Isso é muito atraente para os acadêmicos, pois, em um primeiro entendimento, eles "não perderão tempo estudando coisas que nunca usarão". O uso da palavra "prática" se tornou um mantra na condução de cursos de Administração, Economia e Contabilidade. Tudo o que se faz no ensino, de alguma forma, deve ser "prático" e a necessidade de uma resposta metodológica motiva os professores a sair da zona de conforto para buscar respostas e propostas. Essa promessa de praticidade é muito relevante e deve ser alimentada ao longo do tempo. Ademais, explicitando o que é prática, esse termo é vago para um estudante de graduação, pois envolve também um grau relevante de incerteza quanto ao produto proporcionado. Nem sempre isso é claro aos olhos dos acadêmicos. Igualmente se pode dizer, aos olhos dos professores.

Neste sentido, Bloom et al. (1983) propõem uma abordagem abrangente no que se refere à estruturação de uma disciplina. Iniciando pelo conhecimento, termina na avaliação. Muito embora seja sequencial, não especifica o intervalo de tempo transcorrido entre o primeiro elemento e o último. Posteriormente, Anderson e Krathwohl (2000) revisaram a taxonomia de Bloom, batizando-a de taxonomia revisada, a qual foi utilizada neste trabalho como pano de fundo da análise.

Por outro lado, existem inúmeras tensões durante o período de tempo em que o curso se desenvolve. A concorrência com outras disciplinas, por exemplo, constitui-se em elemento relevante, pois o tempo do estudante é disputado por várias outras atividades, inclusive com o emprego. A diferença de tipos de disciplinas (formação geral, formação específica, obrigatórias, optativas, por exemplo) nem sempre se mostra clara para que os estudantes se posicionem perante um novo desafio.

Para um estudante que conheça a realidade de uma organização, por exemplo, se existe alinhamento entre o emprego e a escola, o acadêmico percebe a praticidade de uma maneira. Se essa experiência não existe, por mais que a disciplina proporcione benefícios, deixa de ser percebida como "prática". Esse quadro, com uma percepção pragmática de curto prazo, é parte do mundo vivido pelo docente ao ministrar uma disciplina pela abordagem PBL, em um curso relacionado com negócios. Particularmente, Ribeiro e Mizucame (2004) referem-se a duas críticas dos estudantes quanto ao método PBL, que são: (i) a identificação e tratamento do problema antes da teoria gerou insegurança nos estudantes que não haviam tido contato mais amplo com os assuntos anteriormente e (ii) a organização dos conteúdos proporcionados pelo método PBL gerou instabilidade na compreensão de acadêmicos acostumados com métodos mais estruturados e lógicos de ensino. Os dois aspectos criaram uma tensão nos estudantes e o contraponto entre o fator atraente do PBL (a sua praticidade) e uma desvantagem (a incerteza).

Dessa maneira, o problema orientador da pesquisa é: como manter o interesse do estudante frente ao desafio da tensão prática x incerteza, em disciplinas, na área de negócios, estruturadas sob o enfoque do método PBL? 
A ação geral que direcionou o estudo é discutir, dentro das perspectivas do método PBL, estratégias para manter $\mathrm{o}$ interesse do estudante perante a disciplina, face à tensão prática $\mathrm{x}$ incerteza. Entre as ações específicas que direcionaram a reflexão dos pesquisadores, destacamse: (a) discutir a aplicação do método na perspectiva da taxonomia de Bloom, (b) analisar as vantagens e críticas ao método PBL e (c) avaliar o interesse dos estudantes, face à tensão pragmatismo versus incertezas na aplicação do método em uma disciplina na área de negócios. Assim, a seção revisão da literatura apresenta e discute a taxonomia de Bloom revisada e a estrutura básica e principais vantagens e críticas ao método PBL; a seção método descreve as trajetórias da pesquisa e características do caso trabalhado; na seção seguinte são apresentadas as observações e análises do estudo; e, por fim, são relatadas as principais conclusões da pesquisa.

\section{REVISÃO DA LITERATURA}

\subsection{A Taxonomia Bloomiana revisada}

Bloom et al. $(1974,1983)$ são referências fundamentais para prática docente e reflexão sobre o ensino e aprendizagem. Inclusive para estudo e implementação do PBL (DUCH, 2001b).

Neste sentido, Galhardi e Azevedo (2013) relatam que a taxonomia de Bloom tem se mostrado bastante útil em uma variedade de situações relacionadas ao processo de ensino e aprendizagem. Embora existam outras taxonomias educacionais e sistemas hierárquicos, a taxonomia de Bloom tem se destacado nos últimos 50 anos. Atualmente, com as mudanças no perfil dos estudantes, avanços tecnológicos e outras dificuldades intrínsecas da docência, cresce a busca por ferramentas que auxiliem no processo de ensino e aprendizagem. Porém, pesquisadores e educadores têm encontrado dificuldades e discrepâncias na classificação de questões em cada nível da taxonomia de Bloom.

Ferraz e Belhot (2010) destacam que a taxonomia elaborada por Bloom e sua equipe no final da década de 50 objetivou auxiliar no planejamento, organização e controle de objetivos de aprendizagem. A taxonomia aborda os domínios cognitivo, afetivo e psicomotor, embora a taxonomia do domínio psicomotor tenha sido elaborada por outros autores. Ademais, os autores salientam que todos os domínios foram amplamente divulgados por pesquisadores diferentes em vários momentos, entretanto o domínio cognitivo é o mais conhecido e utilizado. A taxonomia possibilitou a padronização da linguagem e novas discussões relacionadas à definição de objetivos instrucionais. Com isso, instrumentos de aprendizagem puderam ser trabalhados de forma mais estruturada e integrada, inclusive considerando os avanços tecnológicos.

Quanto ao domínio cognitivo, as categorias do nível mais simples ao mais complexo são: (i) conhecimento (também denominado memorização), (ii) compreensão, (iii) aplicação, (iv) análise, (v) síntese e (vi) avaliação. Por sua vez, o domínio afetivo considera as seguintes categorias: (i) receptividade, (ii) resposta, (iii) valorização, (iv) organização e (v) caracterização por um valor ou complexo de valores. Aliada às categorias, a existência de palavras (verbos) proporcionou a operacionalização da taxonomia na montagem de objetivos, atividades e avaliações em cursos e currículos.

Posteriormente, um participante de seu grupo de pesquisa, Lorin Anderson, questionou a taxonomia, propondo alguns ajustes aos quais denominou taxonomia revisada de Bloom.

A primeira etapa da revisão focou a observação detalhada das categorias e subcategorias do conhecimento. Essa etapa levou à divisão do conhecimento em dois grupos, conhecimento como processo e conhecimento como conteúdo assimilado. Na dimensão processo cognitivo, 
as cinco categorias da taxonomia original foram renomeadas ou alteradas para: lembrar, entender, aplicar, analisar, avaliar e criar (FERRAZ; BELHOT, 2010).

Essa revisão, além de ajustes semânticos, proporcionou atualização da abordagem e uma certa redução de ambiguidade em relação ao que esperar na evolução. A estruturação da proposta de Anderson (ANDERSON; KRATHWOHL, 2000) leva em conta (Quadro 1).

\begin{tabular}{|c|c|c|}
\hline Dimensões & Especificação & Verbos \\
\hline Lembrar & $\begin{array}{l}\text { Reconhecer e reproduzir ideias } \\
\text { Distinguir e selecionar dada informação }\end{array}$ & $\begin{array}{l}\text { Reconhecendo } \\
\text { reproduzindo }\end{array}$ \\
\hline Entender & $\begin{array}{l}\text { Estabelecer uma conexão entre o novo conhecimento e o } \\
\text { existente } \\
\text { Efetivada quando o aprendiz explica com suas próprias } \\
\text { palavras }\end{array}$ & $\begin{array}{l}\text { Interpretando, } \\
\text { exemplificando, } \\
\text { classificando, resumindo, } \\
\text { inferindo, comparando e } \\
\text { explicando }\end{array}$ \\
\hline Aplicar & $\begin{array}{l}\text { Executar ou usar procedimentos numa situação específica ou } \\
\text { situação nova }\end{array}$ & $\begin{array}{ll}\text { Executando } & \text { ou } \\
\text { implementando }\end{array}$ \\
\hline Analisar & $\begin{array}{l}\text { Dividir a informação em partes relevantes, importantes e não } \\
\text { importantes e entender a relação entre as partes }\end{array}$ & $\begin{array}{l}\text { Diferenciando, organizando, } \\
\text { atribuindo e concluindo }\end{array}$ \\
\hline Avaliar & $\begin{array}{l}\text { Realizar julgamento baseado em critérios e padrões } \\
\text { qualitativos e quantitativos ou de eficiência e eficácia }\end{array}$ & Checando e criticando \\
\hline Criar & $\begin{array}{l}\text { Colocar elementos juntos com o objetivo de criar uma nova } \\
\text { visão, solução, estrutura ou modelo utilizando conhecimentos } \\
\text { previamente obtidos }\end{array}$ & $\begin{array}{l}\text { Generalizando, planejando e } \\
\text { produzindo }\end{array}$ \\
\hline
\end{tabular}

Fonte: Adaptado de Ferraz e Belhot (2010)

De forma semelhante à taxonomia original, a categoria conhecimento está relacionada ao conteúdo e passou a conter quatro subcategorias. As três primeiras, efetivo, conceitual e procedural, foram reorganizadas para usar uma terminologia mais clara e que possibilitasse reconhecer as diferenças psicocognitivas desenvolvidas, e a última relacionada ao conceito de metacognição tem crescido em importância, pois a possibilidade de autoaprendizagem e o controle do aprendizado vinculado à autonomia de aprender tornou-se um processo cada vez mais consciente e passível de medição (FERRAZ; BELHOT, 2010). Essas subcategorias abrangem os seguintes aspectos do conhecimento:

a) efetivo ou factual: conhecimento básico que o discente deve ter para acompanhar o processo.

Os conhecimentos devem ser apenas lembrados, não necessariamente entendidos;

b) conceitual: inter-relação entre conceitos básicos que precisam ser conectados. Esquemas, estruturas e modelos precisam ser entendidos. Antes de aplicar o modelo, é fundamental entendê-lo;

c) procedural: conhecimento do "como realizar alguma coisa" utilizando modelos, estruturas e algoritmos. O conhecimento abstrato passa a ser estimulado num contexto único e não interdisciplinar;

d) metacognitivo: reconhecimento da cognição em geral e da consciência da amplitude e profundidade adquirida de um dado conhecimento. Relacionado a interdisciplinaridade, conhecimento estratégico e autoconhecimento.

O cruzamento das dimensões conhecimento e processo cognitivo permite um relevante modelo para análise, denominado tabela bidimensional da taxonomia de Bloom (Quadro 2). Objetivos podem ser estabelecidos dentro de cada quadrante, levando em conta atingir a dimensão do processo cognitivo ambicionada que é criar. A taxonomia aparenta certa estabilidade, sendo o conhecimento definido a priori, contudo, na utilização do PBL, o estudante define o problema a ser tratado, o que torna a visão da taxonomia de Bloom algo muito mais dinâmico e volátil. Nesse sentido, os conceitos a serem tratados só podem ser definidos depois que o problema a ser tratado se torna claro. Contudo, a tabela bidimensional 
da taxonomia de Bloom possibilita, na visão de Ferraz e Belhot (2010), um direcionamento para que educadores possam planejar melhor os objetivos instrucionais e orientar, de forma coerente, clara e concisa, o processo de ensino, de maneira que efetive o processo de aprendizagem.

Quadro 2 - Processo cognitivo e conhecimentos

\begin{tabular}{|l|c|c|c|c|c|c|}
\hline \multirow{2}{*}{$\begin{array}{c}\text { Dimensão do } \\
\text { Conhecimento }\end{array}$} & \multicolumn{5}{c|}{ Dimensão do Processo Cognitivo } \\
\cline { 2 - 7 } & Lembrar & Entender & Aplicar & Analisar & Avaliar & Criar \\
\hline Efetivo ou factual & Objetivo 1 & & & & & \\
\hline Conceitual & & Objetivo 2 & Objetivo 3 & Objetivo 4 & & \\
\hline Procedural & & & & Objetivo 5 & Objetivo 6 & Objetivo 7 \\
\hline Metacognitivo & \multicolumn{2}{|c|}{ Conhecimento } & \multicolumn{2}{c|}{ Competência } & & Habilidade \\
\hline
\end{tabular}

Fonte: Adaptado de Ferraz e Belhot (2010)

O design da taxonomia de Bloom revisada, embora mantenha a hierarquia de complexidade e dependência, do mais simples para o mais complexo como na original, é mais dinâmico e flexível e tem se mostrado efetivo no desenvolvimento de processos educacionais. Portanto, pode auxiliar na implementação de objetivos, estratégias de ensino e conteúdos em disciplinas e curso que fazem uso do método PBL e outros. Ainda que o método PBL seja focado na aprendizagem dos estudantes, isso pode ocorrer de maneira mais efetiva por meio do alinhamento dos objetivos da disciplina ao processo educacional orientado pela taxonomia de Bloom revisada.

\subsection{PBL como Estrutura Básica}

O método PBL surge como mais uma proposta de aprendizagem construtivista, focada nos estudantes. Segundo Komatsu, Zanolli e Lima (1998), esse método foi desenvolvido na Universidade de Macmaster, Canadá, no final da década de 60, quando um grupo de docentes estruturou um novo programa para o curso de medicina. Desse centro universitário, o método foi disseminado para a universidade de Maastricht na Holanda, em 1980; para Harvard e Cornell nos Estados Unidos da América (EUA); dentre outras mais de 60 escolas; tendo sido também implementado no Brasil na Faculdade de Medicina de Marília (Famema), em 1997, e na Universidade Estadual de Londrina (UEL), no curso de medicina em 1998.

Observa-se a disseminação do método PBL nos cursos de medicina, mas em outras áreas também há inúmeras experiências de implementação do método. Deelman e Hoeberigs (2009) relatam que desde sua criação, em 1986, a Faculdade de Economia e Administração da Universidade de Maastricht adotou o enfoque educacional usado na Faculdade de Medicina, com proposta multidisciplinar, inexistência de bibliografia prévia e prova de evolução no curso, sob o enfoque do PBL.

Ainda, em 2005, foi criada a Escola de Artes, Ciências e Humanidades (EACH), campus Leste da Universidade de São Paulo (USP), com uma dezena de cursos, em diferentes áreas do conhecimento, tais como Ciências da Atividade Física, Gerontologia, Gestão Ambiental, Gestão de Políticas Públicas, Lazer e Turismo, Marketing, Obstetrícia, Sistema de Informação, e Têxtil e Moda. Desses, seis cursos foram organizados sob três eixos centrais, formação específica e geral, ambos com oito horas semanais cada e formação científica e profissional, por meio da resolução de problemas, com quatro horas semanais (ARAÚJO; ARANTES, 2009).

Entre as instituições de ensino superior destacam-se, no uso do método PBL, segundo Araújo e Arantes (2009), a Universidade de Aalborg, na Dinamarca, e Maastricht, na Holanda, referências mundiais, com mais de 30 anos de experiência acumulada em várias áreas do 
conhecimento. Os autores salientam que há diversas formas de compreensão e implementação da aprendizagem baseada em problemas (ABP), todavia predominam, na maioria das instituições, as bases teóricas de Piaget, Vygotsky, Dewey, Lewin e Bruner, e o princípio de focar a aprendizagem dos estudantes e não o ensino.

O método PBL tem sido usado com êxito em várias áreas do conhecimento, Ciências da Saúde, Ciências Sociais, Engenharias, Artes e Humanidades, demonstrando uma vertente proeminente para formação profissional e social na contemporaneidade. Ademais, apresenta foco na aprendizagem ativa, centrada no estudante, por meio do estudo autônomo e discussão de problemas atuais, relacionados à disciplina ou a outros contextos sociais e econômicos. Segundo Brandão, Lessadrini e Lima (1998), o método PBL está associado às teorias construtivistas, em que o conhecimento não é absoluto, e sim construído pelo estudante por meio de seu conhecimento pregresso e sua percepção global, dimensionando a necessidade de aprofundar, amplificar e integrar o conhecimento. Ainda quanto às características do método PBL, a aprendizagem ocorre por meio de ação motivada, não decorrendo de imposição, mas do nível crítico de conhecimento do estudante, ao qual se chega pelo processo de compreensão, reflexão e crítica (VILA; VILA, 2007, p. 1180 apud DECKER; BOUHUIJS, 2009, p. 186).

Segundo Enemark e Kjaersdam (2009, p. 18), o método PBL favorece: (i) integração entre universidade e empresa, (ii) integração entre pesquisa e empresa, (iii) soluções interdisciplinares, (iv) a busca de conceitos mais atuais, (v) a atualização dos professores, (vi) a criatividade e a inovação, (vii) as habilidades de desenvolvimento de projetos, (viii) habilidades de comunicação, (ix) o aprendizado eficaz, (x) a criação de entorno social. Esses benefícios são fundamentais para tornar o aprendizado "prático" e ser considerado relevante no ambiente das instituições de ensino que se voltam para negócios.

O processo de ensino e aprendizagem pelo método PBL gera uma dinâmica que possibilita a aproximação do estudante com a prática, isso, por meio da inserção e intervenção na realidade da área de formação. O método é estruturado por meio do questionamento do fenômeno ou projetos e requer dos envolvidos a investigação, reflexão sobre o quadro delimitado e comunicação das observações e resultados, logo congrega prática profissional, pesquisa e ensino.

Alinhado com a realidade e dinâmica empresarial e profissional, o método exige a formação de grupos de estudos. Komatsu, Zanolli e Lima (1998) informam que, na Faculdade de Medicina de Marília, as sessões tutoriais são constituídas de cinco a oito estudantes, orientados por um tutor e eventualmente por um cotutor, com reuniões duas vezes por semana, em dias não contíguos para que haja tempo para estudo entre as sessões. Sobre o assunto, Pinto, Santos e Pereira (2004) sugerem os seguintes participantes e papéis no desenvolvimento do método PBL (Quadro 3).

Ademais, Nobre et al. (2006) sugerem uma estrutura mais sintética. O facilitador (professor), responsável por auxiliar a apreensão de conteúdo, sem ser o principal disseminador de conhecimento; o aprendiz (estudante), responsável pela busca ativa do conhecimento; e o tutor, responsável por auxiliar os aprendizes nas dificuldades de conteúdo da disciplina e do problema.

Outro aspecto na estruturação do método é o delineamento e gerenciamento das etapas de trabalho. Araújo e Arantes (2009), baseados na experiência da EACH, sugerem as seguintes fases e atividades no uso do método PBL (Quadro 4).

Neste sentido, Pinto, Santos e Pereira (2004) sugerem as seguintes etapas que podem ser complementares à abordagem anterior: (i) ponto de partida: ler atentamente o problema/tema e esclarecer os termos desconhecidos, (ii) tempestade de ideias: associar livremente ideias relacionadas ao cenário do tema/problema, (iii) sistematização: formulação de hipóteses/proposições, (iv) formulação de questões de aprendizagem: questões que auxiliem na solução do problema, (v) estabelecer metas de aprendizagem: formular metas que permitam 
dar resposta às questões e o plano de ação para cumpri-las, (vi) avaliação do processo: avaliação do processo e da aprendizagem, (vii) seguimento: desfazer equívocos, avaliar metas de aprendizagem e seguir adiante.

Quadro 3 - Participantes e papéis no método PBL

\begin{tabular}{|c|l|}
\hline Participantes & \multicolumn{1}{c|}{ Papéis } \\
\hline Estudantes & $\begin{array}{l}\text { Colaborar com os tutores, coordenadores e secretários durante a sessão; ler o problema } \\
\text { atentamente; relacionar os termos desconhecidos; expressar as suas ideias; apontar as } \\
\text { hipóteses relacionadas ao problema; eleger ideias relevantes; estabelecer metas de } \\
\text { aprendizagem; definir o cronograma de atividades; estudar; pesquisar; manter contato } \\
\text { com os tutores; elaborar trabalhos solicitados pelos tutores, entre outros. }\end{array}$ \\
\hline Conferencista & Participar de sessões teóricas realizando palestras, debates etc. \\
\hline Consultor & Orientar os estudantes e esclarecer possíveis dúvidas. \\
\hline $\begin{array}{c}\text { Coordenador } \\
\text { (estudante) }\end{array}$ & $\begin{array}{l}\text { Garantir que a discussão do problema se dê de forma metódica e que todos os membros } \\
\text { do grupo participem da discussão. }\end{array}$ \\
\hline $\begin{array}{c}\text { Secretário } \\
\text { (estudante) }\end{array}$ & $\begin{array}{l}\text { Registrar fielmente e comrigor todas as discussões e eventos ocorridos no grupo tutorial. } \\
\text { Tutor }\end{array}$ \\
$\begin{array}{l}\text { Conhecer os objetivos e a estrutura do módulo temático; assumir a responsabilidade } \\
\text { secretário e, quando necessário, fazer a escolha dos mesmos; estimular, apoiar e ajudar } \\
\text { os estudantes de modo que participem ativamente no processo de construção de sua } \\
\text { aprendizagem; participar da elaboração do problema e avaliar os grupos e as sessões } \\
\text { tutoriais. }\end{array}$ \\
\hline
\end{tabular}

Fonte: Pinto, Santos e Pereira (2004)

Quadro 4 - Fases e atividades na estruturação do método

\begin{tabular}{|l|l|}
\hline \multicolumn{1}{|c|}{ Fases } & \multicolumn{1}{|c|}{ Atividades } \\
\hline & $\begin{array}{l}\text { a) aproximação da temática a ser estudada; } \\
\text { b) elaboração do problema pelo grupo; } \\
\text { c) mapeamento e busca de informações sobre o problema; } \\
\text { d) Análise do problema elaboração de hipóteses que auxiliem na compreensão do fenômeno; } \\
\text { planejamento da pesquisa. } \\
\text { e) definições de estratégias para se responder ao problema; } \\
\text { f) elaboração do projeto de pesquisa. }\end{array}$ \\
\hline $\begin{array}{l}\text { 2) Desenvolvimento de } \\
\begin{array}{l}\text { ações que levem à } \\
\text { resolução do problema. }\end{array}\end{array}$ & $\begin{array}{l}\text { a) desenvolvimento de estudos (individuais e em grupo), pesquisas e } \\
\text { intervenções. }\end{array}$ \\
\hline $\begin{array}{l}\text { 3) Produção do relatório } \\
\text { científico. }\end{array}$ & $\begin{array}{l}\text { a) socialização dos resultados; } \\
\text { b) produção do relatório científico. }\end{array}$ \\
\hline
\end{tabular}
Fonte: Araújo e Arantes (2009)

Adicionalmente, Enemark e Kjaersdam (2009) ressaltam que todos os estudantes têm de saber explicar os resultados de seus estudos e pesquisas aos colegas do grupo. Essa exigência indica a aquisição de conhecimentos teóricos e profissionais, enquanto no ensino tradicional, os estudantes normalmente se limitam a memorizar o que o professor ensinou e transcrever nas provas; no modelo orientado pelo PBL, os conhecimentos são avaliados por meio de pesquisas e debates em grupo.

Para tanto, há a necessidade de clareza das etapas, atividades, normas de formatação e estruturação do projeto e relatório científico e adoção de postura distinta daquela requerida, em geral, no ensino tradicional, na qual, muitas vezes, os estudantes vão à escola para assistir aulas. Assim, o método exige dos estudantes criatividade, liderança, espírito investigativo, relacionamento interpessoal e expressão escrita e oral em muitas etapas.

Também os professores passam a gerenciar aulas sem o controle e ritmo tão estruturado e uniforme como ocorrem nas aulas expositivas, ou seja, o método requer mais liderança, direcionamento, estímulo e cobrança do andamento dos trabalhos. Portanto, em muitos casos, a efetividade do método e resultados ficam prejudicados ou tornam-se questionáveis. Komatsu, 
Zanolli e Lima (1998) relatam que o maior desafio da capacitação docente é a mudança cultural, do processo centrado no professor, em disciplinas, para focado no estudante e no ensino e aprendizagem. Informam que, na Famema, os docentes participam de oficinas de capacitação de tutores e por experiências de cotutoria, em média por 12 semanas, antes de assumirem a função de tutor.

A capacitação de professores, processo de autoavaliação e programas de qualidade educacional são práticas adotadas nas universidades pioneiras no uso do PBL, como as de Aalborg e Maastricht. $O$ processo de avaliação e formação certamente auxiliam no gerenciamento dos cursos e implementação mais efetiva do método.

\subsection{Principais Vantagens e Críticas ao PBL}

Antes de evidenciar críticas, o estudo salienta algumas vantagens do método PBL. Neste sentido, Moesbi (2009) evidencia que o método PBL mostra-se superior ao ensino tradicional, ao comparar a formação de habilidades dos estudantes na Universidade Técnica da Dinamarca com a Universidade de Aalborg (Gráfico 1).

Gráfico 1- Comparação das habilidades dos estudantes pelo método tradicional e PBL

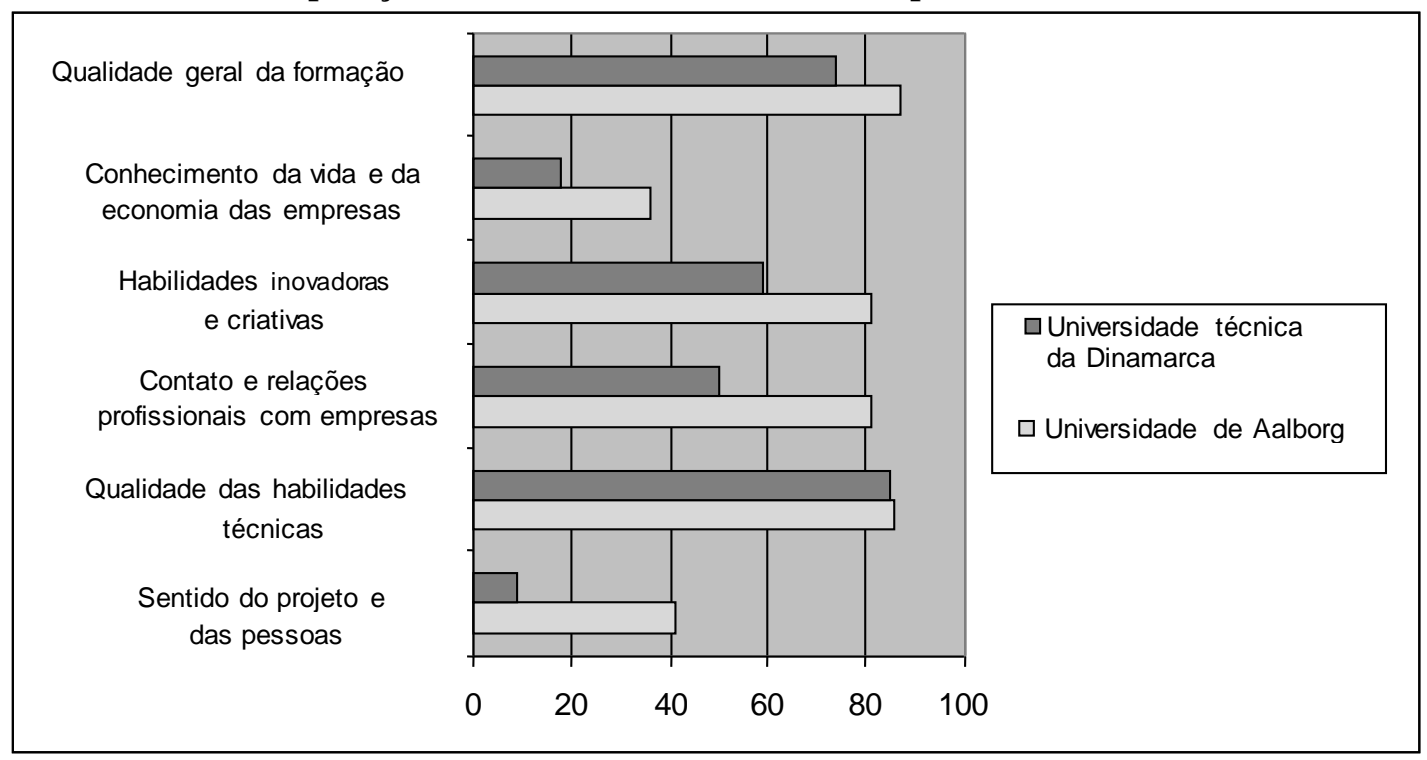

Fonte: Nyhedsmagasinet ingeniorem (2004) apud Moesby (2009, p. 75)

O gráfico demonstra a ampliação da formação de habilidades pelo método PBL, principalmente quanto ao conhecimento das empresas, desenvolvimento de inovação e criatividade, contato e relação profissional com as empresas e compreensão do sentido de projeto e das pessoas. Ademais, Komatsu, Zanolli e Lima (1998) reúnem estudos que evidenciam que estudantes de programas que usaram o PBL desenvolvem melhores habilidades de relacionamento interpessoal, integração biopsicossocial, utilização de biblioteca e recursos educacionais, educação permanente, aprendizagem autodirigida, satisfação profissional e desenvolvimento cognitivo. Contudo, relatam estudos que consideram a formação pelo método indistinguível da formação tradicional e outras pesquisas que evidenciam escassez de estudos de boa qualidade ou incompletos sobre o assunto.

Por outro, há diversas críticas ao método e relatos de insucesso. Deelman e Hoeberigs (2009) informam que, durante muitos anos, a Universidade de Maastricht foi a única a usar o método PBL, enfoque que suscitava oposição e ceticismo. Para mudar esse quadro foi preciso demonstrar que o sistema de ensino era tão eficaz quanto o tradicional, para tanto, muito foi investido em pesquisa em educação e programas de qualidade. Atualmente a universidade é 
respeitada, tem elementos de seu modelo educativo no currículo de outras instituições de ensino superior e estudos comparativos entre universidades holandesas destacam o alto grau de satisfação dos estudantes com a qualidade de formação e estrutura da Universidade de Maastricht. Entretanto, relatam que adotar o método na Faculdade de Economia e Administração, nos moldes do curso de Medicina, inicialmente não foi uma boa opção, pois o enfoque multidisciplinar foi complexo em um currículo com orientação mais variada que o de Medicina; acadêmicos e professores sentiam-se inseguros em trabalhar sem bibliografia prévia, pautando-se em material muito superficial ou específico e a prova de evolução não funcionava no novo contexto.

Pelos relatos ficou evidente que o modelo educacional, orientado pelo PBL, adotado no curso de Medicina não se adequou ao novo curso de Economia e Admi nistração e gerou prejuízos no funcionamento do curso e formação dos estudantes. Araújo e Arantes (2009) reconhecem que, na estruturação dos cursos da $\mathrm{EACH}$, o ciclo básico de formação científica e cultural, por meio da resolução de problemas, traz inúmeras vantagens para a formação dos estudantes, mas as aulas expositivas e outras estratégias de ensino e aprendizagem podem conviver no mesmo currículo e enriquecer o projeto acadêmico.

Nobre et al. (2006) relatam que o uso do método PBL aplicado no ensino das disciplinas Sistemas Embarcados e de Tempo Real, ministradas na graduação e pós-graduação de Engenharia Eletrônica e Computação do Instituto Tecnológico de Aeronáutica (ITA), foi considerado um sucesso; entretanto foram constatadas dificuldades na sua ministração, devido à inexperiência dos estudantes no trabalho em grupo, que prejudicou negociações e decisões relativas ao projeto; além da falta de liderança e habilidade para representar o grupo durante a fase de integração do protótipo. Os autores usaram listas de exercícios, provas bimestrais, elaboração de projetos e socialização do produto final, para exercitar habilidades e gerar mecanismos de acompanhamento e mensuração do andamento do projeto, com isso as dificuldades como a superação da postura passiva dos estudantes frente ao seu aprendizado, o planejamento de estudo individualizado e a amplitude e profundidade do conteúdo pesquisado foram superadas integralmente ou parcialmente no delineamento do projeto.

Ficou evidente que o processo de avaliação amplo tinha como princípio proporcionar a dinâmica de aprendizagem de conhecimento e habilidades necessárias ao desenvolvimento e acompanhamento do projeto. Ademais, esse processo de formalização ora estava focado no indivíduo, ora na equipe e alinhado com cada etapa do projeto. Em síntese, os mecanismos de formalização mitigaram muitas dificuldades encontradas na gestão das disciplinas, contudo outras deficiências dos estudantes permaneceram, geraram prejuízo ao processo e afetaram os resultados do trabalho, mas não de forma significante.

Ribeiro e Mizukami (2004), ao implementar o PBL na disciplina Teoria Geral da Administração na pós-graduação em Engenharia da Produção na Universidade de São Carlos, informam que a maioria dos estudantes julgou positivamente a metodologia, por promover habilidades interpessoais, de pesquisa, de solução de problema e no desenvolvimento de trabalhos em equipe; todavia, apontaram as seguintes críticas ao método (Quadro 5).

Os autores relatam que alguns problemas foram mitigados ou solucionados com a adoção de tempo de fechamento no início das aulas, a alternância de papéis nas equipes, redistribuição dos estudantes em novos grupos a partir do meio do semestre e autoavaliações informais do processo e desempenho. Ainda, as deficiências listadas podem ser gerenciadas por meio das ideias sugeridas por outros autores, tais como a elaboração de diários semanais individuais, documentando a participação do estudante e feedback construtivo imediato anônimo dos colegas, após as socializações. 


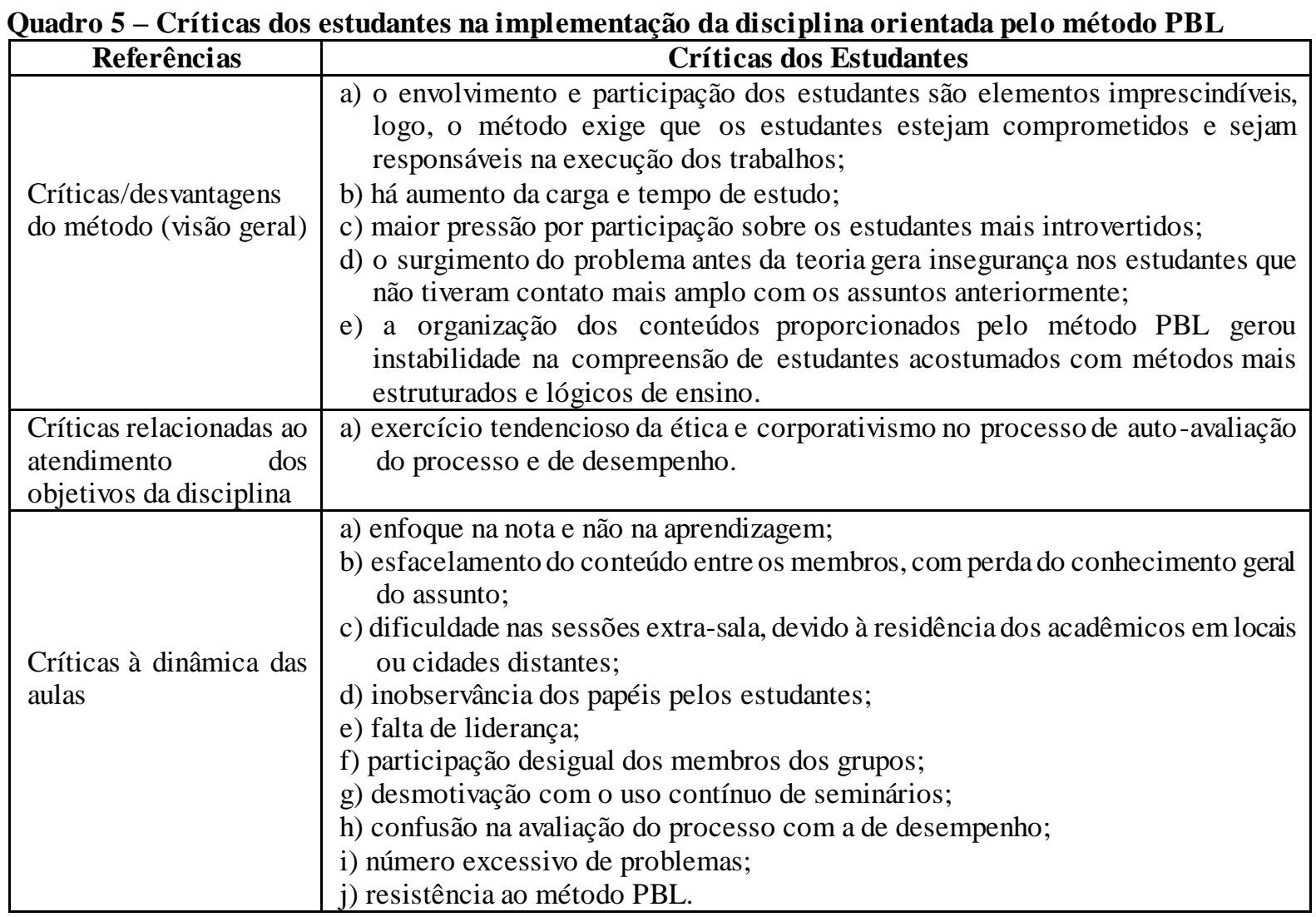

Fonte: Ribeiro e Mizukami (2004)

Por fim, Komatsu, Zanolli e Lima (1998) informam que o sucesso, como o da Universidade de Macmaster, deve-se não somente à adoção do método PBL, mas ao desenvolvimento institucional rumo às necessidades da sociedade. Em síntese, a estruturação de disciplinas sob o enfoque do PBL requer do professor postura e habilidades distintas daquelas exigidas nas disciplinas com enfoque convencional; elaboração de mecanismos que possibilitem o gerenciamento do processo e das tensões geradas pela nova dinâmica na aprendizagem dos estudantes em sala e extrassala, e capacitação do docente para que haja seu aprimoramento contínuo, assim, a sua prática poderá tornar-se mais efetiva.

\section{MÉTODO E DESCRIÇÃO DO CASO TRABALHADO}

A disciplina utilizada foi criada especialmente para a implementação do método PBL. Como tema norteador foi escolhido: impactos do sistema de informações gerenciais sobre o gerenciamento das organizações. Esse tema foi escolhido, pois permite aos estudantes do Curso de Ciências Contábeis identificarem uma vasta gama de oportunidades dentro das organizações. Todos os estudantes, um grupo inicialmente de 18 participantes, mas que foram reduzidos para 7, trataram dois diferentes problemas, depois de sessões tutoriais e de socialização. A disciplina foi criada em uma instituição de ensino pública em que o método não é utilizado e não existe compromisso institucional, e a atratividade passa pela percepção de ganho de conhecimento versus esforço. Dessa maneira, o curso oferecido, ao mesmo tempo, era visto como uma oportunidade de oxigenação, mas também como um risco por não se alinhar às demais disciplinas.

Os objetivos explícitos da disciplina, especificados no programa foram:

a) adquirir e utilizar uma base de conhecimento estruturada ao redor de problemas reais encontrados no campo de atuação do profissional em questão. Essa declaração de benefício ao final do curso tinha o desafio de identificar conhecimentos já tratados sobre o tema e 
ativá-los dentro de cada grupo. Por outro lado, novos desafios surgiram no que se refere a conhecimentos não aprofundados em disciplinas e que seriam utilizados pelos alunos;

b) experimentar processo de solução de problema estruturado, eficaz e eficiente. As questões técnicas surgiram no sentido de identificar qual PBL seria utilizado, em termos de referencial e peculiaridades de modelo;

c) avaliar a solução proposta levando em conta diferentes realidades e pressões. A autoavaliação e a avaliação por pares, efetivada na disciplina, não é uma prática do curso, o que aumentou a incerteza dos participantes;

d) desenvolver habilidades de aprendizagem autônoma eficaz e de habilidades de trabalho em grupo.

A disciplina foi estruturada levando em conta o seguinte referencial teórico e cronograma de atividades, descritos no programa e detalhados nos planos de aulas, sintetizad os no Quadro 6 abaixo. As referências descritas no quadro, programa e outras foram consideradas, tratadas e, em alguns casos, adaptadas na preparação da disciplina em decorrência da quantidade de estudantes, à disponibilidade física de espaço, disponibilidade de tutores e horários formais. As referências bibliográficas gerais do tema norteador foram descritas no programa e referências específicas de cada problema foram disponibilizadas no site do Erudito, programa usado pela instituição para gestão do envio e recebimento de material, ou enviadas por $e$-mail.

Quadro 6 - Estrutura conceitual da disciplina (* OD: objetivos da disciplina)

\begin{tabular}{|c|c|c|c|c|c|c|}
\hline Descrição & Referência & Mecanismos & $\begin{array}{c}\text { Dim. de } \\
\text { Conhecim. }\end{array}$ & $\begin{array}{c}\text { Dim. } \\
\text { Cognitiva }\end{array}$ & Agente & Od* \\
\hline $\begin{array}{l}\text { Definição do } \\
\text { tema }\end{array}$ & $\begin{array}{l}\text { Araújo e } \\
\text { Arantes, } 2009\end{array}$ & $\begin{array}{l}\text { Evidenciado no } \\
\text { Programa } \\
\text { Aula expositiva } \\
\text { dialogada }\end{array}$ & & & Docente & \\
\hline $\begin{array}{l}\text { Apresentar a } \\
\text { metodologia } \\
\text { aos } \\
\text { estudantes }\end{array}$ & $\begin{array}{l}\text { White III, 2001; } \\
\text { Enemark e } \\
\text { Kjaersdam, } \\
2009\end{array}$ & $\begin{array}{l}\text { Ação durante a aula } \\
\text { Aula expositiva } \\
\text { dialogada }\end{array}$ & & & Docente & \\
\hline $\begin{array}{l}\text { Informar os } \\
\text { papéis }\end{array}$ & $\begin{array}{l}\text { Pinto, Santos e } \\
\text { Pereira, 2004; } \\
\text { Nobre et al., } \\
2006\end{array}$ & $\begin{array}{l}\text { Ação durante a aula } \\
\text { Aula expositiva } \\
\text { dialogada }\end{array}$ & & & Docente & \\
\hline $\begin{array}{l}\text { Agrupar sem } \\
\text { compromiss } \\
\text { o de } \\
\text { permanência }\end{array}$ & $\begin{array}{l}\text { Duch e Groh, } \\
\text { 2001a }\end{array}$ & Ação durante a aula & & & Docente & \\
\hline $\begin{array}{l}\text { Tempestade } \\
\text { de ideias }\end{array}$ & $\begin{array}{l}\text { Pinto, Santos e } \\
\text { Pereira, 2004 } \\
\text { Duch, 2001a } \\
\text { Duch, 2001b }\end{array}$ & $\begin{array}{l}\text { Discussão em grupo: } \\
\text { estímulo da realidade } \\
\text { conhecida }\end{array}$ & $\begin{array}{l}\text { Factual } \\
\text { Conceitual }\end{array}$ & $\begin{array}{l}\text { Lembrar } \\
\text { Entender } \\
\text { Aplicar }\end{array}$ & Estudante & A, B \\
\hline $\begin{array}{l}\text { Apresentar } \\
\text { problemas e } \\
\text { hipóteses }\end{array}$ & $\begin{array}{l}\text { Duch, 2001a } \\
\text { Duch, 2001b }\end{array}$ & $\begin{array}{l}\text { Plenária durante as } \\
\text { aulas }\end{array}$ & $\begin{array}{l}\text { Procedural } \\
\text { Metacognitivo }\end{array}$ & $\begin{array}{l}\text { Analisar } \\
\text { Avaliar } \\
\text { Criar }\end{array}$ & Estudante & $\begin{array}{l}\text { A, B, } \\
\text { C }\end{array}$ \\
\hline $\begin{array}{l}\text { Votação } \\
\text { para escolha } \\
\text { dos } \\
\text { problemas }\end{array}$ & & $\begin{array}{l}\text { Plenária durante as } \\
\text { aulas: escolha dos } \\
\text { lideres e empresas }\end{array}$ & $\begin{array}{l}\text { Procedural } \\
\text { Metacognitivo }\end{array}$ & $\begin{array}{l}\text { Analisar } \\
\text { Avaliar } \\
\text { Criar }\end{array}$ & Estudante & $\begin{array}{l}\text { A, B, } \\
\text { C }\end{array}$ \\
\hline $\begin{array}{l}\text { Escolha dos } \\
\text { grupos } \\
\text { definitivos }\end{array}$ & $\begin{array}{l}\text { Duch e Groh, } \\
\text { 2001a }\end{array}$ & $\begin{array}{l}\text { Plenária durante as } \\
\text { aulas }\end{array}$ & Procedural & $\begin{array}{l}\text { Analisar } \\
\text { Avaliar }\end{array}$ & Estudante & $\mathrm{C}$ \\
\hline
\end{tabular}


Fábio Frezatti - Sidnei Celerino da Silva

\begin{tabular}{|c|c|c|c|c|c|c|}
\hline Descrição & Referência & Mecanismos & $\begin{array}{c}\text { Dim. de } \\
\text { Conhecim. }\end{array}$ & $\begin{array}{c}\text { Dim. } \\
\text { Cognitiva }\end{array}$ & Agente & Od* $^{*}$ \\
\hline $\begin{array}{l}\text { Organização } \\
\text { do trabalho e } \\
\text { da equipe }\end{array}$ & $\begin{array}{l}\text { Pinto, Santos e } \\
\text { Pereira, } 2004\end{array}$ & $\begin{array}{l}\text { Ação durante a aula } \\
\text { Reuniões dos grupos } \\
\text { fora de sala de aula }\end{array}$ & Procedural & $\begin{array}{l}\text { Analisar } \\
\text { Avaliar }\end{array}$ & $\begin{array}{l}\text { Docente e } \\
\text { estudantes }\end{array}$ & $\begin{array}{l}\text { A, B, } \\
\text { D }\end{array}$ \\
\hline $\begin{array}{l}\text { Bibliografia } \\
\text { básica }\end{array}$ & & $\begin{array}{l}\text { Disponibilizada em } \\
\text { site e no programa }\end{array}$ & & & Docente & \\
\hline $\begin{array}{l}\text { Pesquisar } \\
\text { empresa e } \\
\text { literatura }\end{array}$ & & $\begin{array}{l}\text { Entrevistas, } \\
\text { documentos, site e } \\
\text { outros materiais. }\end{array}$ & $\begin{array}{l}\text { Conceitual } \\
\text { Procedural }\end{array}$ & $\begin{array}{l}\text { Entender, } \\
\text { Aplicar } \\
\text { Analisar }\end{array}$ & Estudante & $\begin{array}{l}\text { A, B, } \\
\text { D }\end{array}$ \\
\hline $\begin{array}{l}\text { Trazer } \\
\text { material para } \\
\text { discussão }\end{array}$ & & $\begin{array}{l}\text { Compartilhar } \\
\text { material entre os } \\
\text { participantes }\end{array}$ & $\begin{array}{l}\text { Factual } \\
\text { Conceitual }\end{array}$ & $\begin{array}{l}\text { Lembrar } \\
\text { Entender }\end{array}$ & Estudante & $\begin{array}{l}\text { A, B, } \\
\text { D }\end{array}$ \\
\hline $\begin{array}{l}\text { Reuniões } \\
\text { tutoriais - } \\
\text { etapa } 1\end{array}$ & $\begin{array}{l}\text { Araújo e } \\
\text { Arantes, } 2009\end{array}$ & $\begin{array}{l}\text { Discutir andamento, } \\
\text { buscar } \\
\text { conhecimentos e } \\
\text { alternativas para } \\
\text { resolver o problema }\end{array}$ & $\begin{array}{l}\text { Procedural } \\
\text { Metacognitivo }\end{array}$ & $\begin{array}{l}\text { Analisar } \\
\text { Avaliar } \\
\text { Criar }\end{array}$ & $\begin{array}{l}\text { Docente } \\
\text { coordena } \\
\text { Estudante }\end{array}$ & $\begin{array}{l}\mathrm{A}, \mathrm{B}, \\
\mathrm{C}\end{array}$ \\
\hline $\begin{array}{l}\text { Entregar } 1^{\mathrm{a}} \\
\text { versão do } \\
\text { projeto }\end{array}$ & $\begin{array}{l}\text { Araújo e } \\
\text { Arantes, } 2009\end{array}$ & $\begin{array}{l}\text { Estruturação do } \\
\text { projeto }\end{array}$ & $\begin{array}{l}\text { Procedural } \\
\text { Metacognitivo }\end{array}$ & $\begin{array}{l}\text { Analisar } \\
\text { Avaliar } \\
\text { Criar }\end{array}$ & Estudante & $\begin{array}{l}\text { A, B, } \\
\text { C, D }\end{array}$ \\
\hline $\begin{array}{l}\text { Reuniões de } \\
\text { socialização } \\
\text { - etapa } 1\end{array}$ & $\begin{array}{l}\text { Araújo e } \\
\text { Arantes, } 2009\end{array}$ & $\begin{array}{l}\text { Socialização dos } \\
\text { projetos e feedback } \\
\text { dos estudantes e } \\
\text { docentes }\end{array}$ & $\begin{array}{l}\text { Procedural } \\
\text { Metacognitivo }\end{array}$ & $\begin{array}{l}\text { Analisar } \\
\text { Avaliar } \\
\text { Criar }\end{array}$ & $\begin{array}{l}\text { Estudante } \\
\text { Docentes }\end{array}$ & $\begin{array}{l}\text { A, B, } \\
\text { C, D }\end{array}$ \\
\hline $\begin{array}{l}\text { Reuniões } \\
\text { tutoriais - } \\
\text { etapa final }\end{array}$ & $\begin{array}{l}\text { Araújo e } \\
\text { Arantes, } 2009\end{array}$ & $\begin{array}{l}\text { Discutir andamento, } \\
\text { solucionar dúvidas e } \\
\text { questionar } \\
\text { alternativas para } \\
\text { resolver o problema. } \\
\text { Deve ficar claro o } \\
\text { nível de } \\
\text { operacionalização } \\
\text { esperado }\end{array}$ & $\begin{array}{l}\text { Procedural } \\
\text { Metacognitivo }\end{array}$ & $\begin{array}{l}\text { Analisar } \\
\text { Avaliar } \\
\text { Criar }\end{array}$ & $\begin{array}{l}\text { Docente } \\
\text { coordena } \\
\text { Estudante }\end{array}$ & $\begin{array}{l}\mathrm{A}, \mathrm{B}, \\
\mathrm{C}\end{array}$ \\
\hline $\begin{array}{l}\text { Reuniões de } \\
\text { socialização } \\
\text { - etapa final }\end{array}$ & $\begin{array}{l}\text { Araújo e } \\
\text { Arantes, } 2009\end{array}$ & $\begin{array}{l}\text { Socialização do } \\
\text { relatório e feedback } \\
\text { dos estudantes e } \\
\text { docentes }\end{array}$ & $\begin{array}{l}\text { Procedural } \\
\text { Metacognitivo }\end{array}$ & $\begin{array}{l}\text { Analisar } \\
\text { Avaliar } \\
\text { Criar }\end{array}$ & $\begin{array}{l}\text { Estudante } \\
\text { Docentes }\end{array}$ & $\begin{array}{l}\mathrm{A}, \mathrm{B} \\
\mathrm{C}, \mathrm{D}\end{array}$ \\
\hline $\begin{array}{l}\text { Avaliação } \\
\text { do curso }\end{array}$ & $\begin{array}{l}\text { Araújo e } \\
\text { Arantes, 2009; } \\
\text { Allen e White } \\
\text { III, } 2001\end{array}$ & $\begin{array}{l}\text { Formal: formulário } \\
\text { de autoavaliação e } \\
\text { prova } \\
\text { Informal: contato } \\
\text { com os grupos e } \\
\text { percepção do docente }\end{array}$ & Procedural & $\begin{array}{l}\text { Analisar } \\
\text { Avaliar }\end{array}$ & $\begin{array}{l}\text { Docente } \\
\text { Estudante }\end{array}$ & $\mathrm{C}$ \\
\hline
\end{tabular}

Fonte: Dados da pesquisa (2012)

O Quadro 6 mostra as principais etapas percorridas e mecanismos adotados na implementação da disciplina com uso do método PBL. A relevância da sequência e dependência das etapas e de suas peculiaridades foi fundamental para a sua aplicação, além das dimensões de conhecimento e processo cognitivo buscados na trajetória da disciplina e os objetivos do curso que estavam vinculados a cada etapa. Em cada etapa, os estudantes receberam orientações de referências, quando necessário, e passos seguintes para elaboração e resolução do problema, coleta de dados e elaboração e socialização do projeto e relatório final. As principais análises desse processo estão descritas na seção seguinte.

\section{ANÁLISE E DISCUSSÃO DO CASO}

O desenvolvimento da disciplina ocorreu dentro da expectativa do docente com algumas crises entre estudantes, tais como mudança de grupos, reclamações sobre falta de compromisso 
e demanda por tempo maior do que o previsto. Essas percepções foram coletadas por meio de resposta ao formulário de autoavaliação da disciplina e conversas com os acadêmicos durante as sessões tutoriais e feedback do projeto e relatório final.

Levando em conta a perspectiva da taxonomia revista, a análise se volta para relevância e operacionalização de cada atividade, prevista no plano de aulas. Neste sentido, o Quadro 7 evidencia análises de cada etapa do cronograma de atividades da disciplina.

Quadro 7 - Ati vidades e análises da implementação da disciplina (* OD: objetivos da disciplina)

\begin{tabular}{|c|c|c|c|c|c|}
\hline Atividades & $\begin{array}{c}\text { Dim. de } \\
\text { Conhecim. }\end{array}$ & $\begin{array}{c}\text { Dim. } \\
\text { Cognitiva }\end{array}$ & Agente & OD* & Análise \\
\hline $\begin{array}{l}\text { Definição do } \\
\text { tema }\end{array}$ & & & Docente & & $\begin{array}{l}\text { O tema é relevante na carreira dos } \\
\text { estudantes e aparece em várias } \\
\text { disciplinas anteriormente ministradas. }\end{array}$ \\
\hline $\begin{array}{l}\text { Apresentar o } \\
\text { método PL }\end{array}$ & & & Docente & & $\begin{array}{l}\text { Foi apresentado e repetido em várias } \\
\text { aulas, pois parte dos estudantes só } \\
\text { apareceu na } 2^{\mathrm{a}} \text { ou } 3^{\mathrm{a}} \text { aula. }\end{array}$ \\
\hline $\begin{array}{l}\text { Informar os } \\
\text { papéis dos } \\
\text { estudantes } \\
\end{array}$ & & & Docente & & $\begin{array}{l}\text { Foi apresentada em aula específica } \\
\text { sobre a operacionalização do método } \\
\text { PBL e enfatizado em aulas seguintes. }\end{array}$ \\
\hline $\begin{array}{l}\text { Definição do } \\
n^{0} \text { de grupos }\end{array}$ & & & Docente & & $\begin{array}{l}\text { Feita a partir da lista de chamada e } \\
\text { quantidade de estudantes. }\end{array}$ \\
\hline $\begin{array}{l}\text { Tempestade } \\
\text { de ideias }\end{array}$ & $\begin{array}{l}\text { Factual } \\
\text { Conceitual }\end{array}$ & $\begin{array}{l}\text { Lembrar } \\
\text { Entender }\end{array}$ & Estudantes & $\mathrm{A}, \mathrm{B}$ & $\begin{array}{l}\text { Foi desenvolvida grupalmente e } \\
\text { alguns estudantes se sobressaíram. }\end{array}$ \\
\hline $\begin{array}{l}\text { Apresentar } \\
\text { problemas e } \\
\text { hipóteses }\end{array}$ & $\begin{array}{l}\text { Procedural } \\
\text { Metacognitivo }\end{array}$ & $\begin{array}{l}\text { Analisar } \\
\text { Avaliar } \\
\text { Criar } \\
\end{array}$ & Estudantes & $\begin{array}{l}\mathrm{A}, \mathrm{B}, \\
\mathrm{C}\end{array}$ & $\begin{array}{l}\text { Todos os estudantes colocaram } \\
\text { problemas no quadro e identificaram } \\
\text { prováveis hipóteses para o problema }\end{array}$ \\
\hline $\begin{array}{l}\text { Leilão e } \\
\text { votação para } \\
\text { escolha dos } \\
\text { problemas }\end{array}$ & $\begin{array}{l}\text { Procedural } \\
\text { Metacognitivo }\end{array}$ & $\begin{array}{l}\text { Analisar } \\
\text { Avaliar } \\
\text { Criar }\end{array}$ & Estudantes & $\mathrm{C}$ & $\begin{array}{l}\text { Foi reconhecido como um ponto } \\
\text { muito forte para a aceitação da } \\
\text { "prática". }\end{array}$ \\
\hline $\begin{array}{l}\text { Escolha dos } \\
\text { grupos } \\
\text { definitivos }\end{array}$ & Procedural & $\begin{array}{l}\text { Analisar } \\
\text { Avaliar }\end{array}$ & Estudantes & $\mathrm{C}$ & $\begin{array}{l}\text { Ocorreu conforme afinidade e } \\
\text { viabilidade do problema, sendo } \\
\text { considerado elemento forte na } \\
\text { operacionalização da disciplina. }\end{array}$ \\
\hline $\begin{array}{l}\text { Organização } \\
\text { do trabalho e } \\
\text { da equipe }\end{array}$ & Procedural & $\begin{array}{l}\text { Analisar } \\
\text { Avaliar }\end{array}$ & Estudantes & $\mathrm{B}, \mathrm{C}$ & $\begin{array}{l}\text { Ocorreu sem interferência docente, } \\
\text { sendo os papéis identificados dentre } \\
\text { os participantes. }\end{array}$ \\
\hline $\begin{array}{l}\text { Bibliografia } \\
\text { básica }\end{array}$ & & & Docente & & $\begin{array}{l}\text { Identificada pelo docente e monitor e } \\
\text { disponibilizada aos estudantes por } e \text { - } \\
\text { mail. }\end{array}$ \\
\hline $\begin{array}{l}\text { Pesquisar } \\
\text { empresa e } \\
\text { literatura }\end{array}$ & $\begin{array}{l}\text { Conceitual } \\
\text { Procedural } \\
\text { Metacognitivo }\end{array}$ & $\begin{array}{l}\text { Entender } \\
\text { Aplicar } \\
\text { Analisar } \\
\text { Criar }\end{array}$ & Estudantes & $\begin{array}{l}\text { A, B, } \\
\text { D }\end{array}$ & $\begin{array}{l}\text { O contato com a empresa ocorreu de } \\
\text { maneira não estruturada, quando foi } \\
\text { possível. } \\
\text { Ficou claro que a abordagem não foi } \\
\text { planejada e especificada pelos } \\
\text { estudantes. }\end{array}$ \\
\hline $\begin{array}{l}\text { Trazer } \\
\text { material para } \\
\text { discussão } \\
\end{array}$ & Conceitual & $\begin{array}{l}\text { Entender } \\
\text { Aplicar }\end{array}$ & Estudantes & A, B & $\begin{array}{l}\text { Poucos materiais foram } \\
\text { compartilhados, evidenciando baixa } \\
\text { ênfase da etapa anterior. }\end{array}$ \\
\hline $\begin{array}{l}\text { Sessões } \\
\text { tutoriais - } \\
\text { etapa } 1\end{array}$ & $\begin{array}{l}\text { Procedural } \\
\text { Metacognitivo }\end{array}$ & $\begin{array}{l}\text { Analisar } \\
\text { Avaliar } \\
\text { Criar }\end{array}$ & $\begin{array}{l}\text { Docente } \\
\text { coordena } \\
\text { Estudantes }\end{array}$ & $\begin{array}{l}\mathrm{A}, \mathrm{B}, \\
\mathrm{C}\end{array}$ & $\begin{array}{l}\text { Estimular o compromisso entre os } \\
\text { membros e reuniões extra-aula foram } \\
\text { mencionadas. } \\
\text { Trocas de membros ocorreram por } \\
\text { motivos de empatia e agenda. } \\
\text { Muito relevante a ampliação e } \\
\text { redução do problema, experiência } \\
\text { relevante para que possa ser } \\
\text { solucionado. }\end{array}$ \\
\hline
\end{tabular}




\begin{tabular}{|l|l|l|l|l|l|}
\hline \multicolumn{1}{|c|}{ Atividades } & \multicolumn{1}{|c|}{$\begin{array}{c}\text { Dim. de } \\
\text { Conhecim. }\end{array}$} & $\begin{array}{l}\text { Dim. } \\
\text { Cognitiva }\end{array}$ & Agente & OD* & \multicolumn{1}{|c|}{ Análise } \\
\hline $\begin{array}{l}\text { Entregar 1 } \\
\text { versão do } \\
\text { projeto }\end{array}$ & $\begin{array}{l}\text { Procedural } \\
\text { Metacognitivo }\end{array}$ & $\begin{array}{l}\text { Analisar } \\
\text { Avaliar } \\
\text { Criar }\end{array}$ & Estudantes & $\begin{array}{l}\text { A, B, } \\
\text { C, D }\end{array}$ & $\begin{array}{l}\text { Os participantes ignoraram o modelo } \\
\text { apresentado anteriormente. }\end{array}$ \\
\hline $\begin{array}{l}\text { Reuniões de } \\
\text { socialização- } \\
\text { etapa 1 }\end{array}$ & Procedural & $\begin{array}{l}\text { Analisar } \\
\text { Avaliar }\end{array}$ & $\begin{array}{l}\text { Estudantes } \\
\text { Docente }\end{array}$ & $\begin{array}{l}\text { A, B, } \\
\text { C }\end{array}$ & $\begin{array}{l}\text { Apresentações foram de boa } \\
\text { qualidade quanto a expressão, mas } \\
\text { fracas em termos de conteúdo. }\end{array}$ \\
\hline $\begin{array}{l}\text { Sessões } \\
\text { tutoriais - } \\
\text { etapa final }\end{array}$ & $\begin{array}{l}\text { Ponceitual } \\
\text { Procedural }\end{array}$ & $\begin{array}{l}\text { Entender } \\
\text { Analisar } \\
\text { Avaliar }\end{array}$ & $\begin{array}{l}\text { Estudantes } \\
\text { Docente }\end{array}$ & $\begin{array}{l}\text { A, B, } \\
\text { C }\end{array}$ & $\begin{array}{l}\text { Reclamos em termos de concorrência } \\
\text { de atividades com outras disciplinas, } \\
\text { quando da cobrança pelos docentes } \\
\text { do andamento das atividades. }\end{array}$ \\
\hline $\begin{array}{l}\text { Reuniões de } \\
\text { socialização- } \\
\text { etapa final }\end{array}$ & Procedural & $\begin{array}{l}\text { Analisar } \\
\text { Avaliar }\end{array}$ & $\begin{array}{l}\text { Estudantes } \\
\text { Docente }\end{array}$ & B, C & $\begin{array}{l}\text { Apresentações de boa qualidade em } \\
\text { termos de técnica e melhoria em } \\
\text { termos de conteúdo. } \\
\text { Trabalhos focaram mais a questão } \\
\text { conceitual do que propriamente } \\
\text { "prática" do problema. }\end{array}$ \\
\hline $\begin{array}{l}\text { Avaliação do } \\
\text { curso }\end{array}$ & Procedural & $\begin{array}{l}\text { Analisar } \\
\text { Avaliar }\end{array}$ & $\begin{array}{l}\text { Docente } \\
\text { Estudantes }\end{array}$ & C & $\begin{array}{l}\text { O formulário de autoavaliação } \\
\text { evidenciou fraquezas percebidas } \\
\text { pelos docentes em sala e nas } \\
\text { socializações. }\end{array}$ \\
\hline
\end{tabular}

Fonte: Dados da pesquisa (2012)

Além das análises descritas no Quadro 7, outros pontos relevantes ficaram claros no desenvolvimento da disciplina e foram evidenciados abaixo.

Observação 1: Foi fundamental a repetição da metodologia e cronograma de atividade a cada aula (atividades daquela aula, da anterior e da próxima), pois alguns estudantes não perceberam o cronograma de atividades, embora tenha sido discutido e distribuído no primeiro dia de aula e retomado rapidamente nas aulas seguintes. Isso pode ser evidenciado por meio dos seguintes relatos: Estudante 5: "Atribuir nota por entrega de relatórios periódicos". Estudante 4: "Informar no começo como a matéria terá que ser seguida".

A autonomia e responsabilidade dos estudantes não prescindem de mecanismos de controle. Ao contrário, eles foram e são fundamentais. A gestão do tempo para cada atividade foi questionada no sentido de que deveria ser mais bem discutida e ajustada no andamento das aulas. A evidência disso pode ser constatada pela sentença: Estudante 1 -"Disponibilidade de horário de aula para visitar empresa e quebrar o relatório em pequenas entregas".

Observação 2: Tanto o leilão de problemas como a definição de quem seria o líder de cada grupo (quem tivesse apresentado o problema mais viável) e ainda a empresa que serviria de corpo para o trabalho foram vitais para a confiança e legitimidade do modelo perante os estudantes. A interação deles nesse processo chegou próxima do entusiasmo. Ainda assim, a formação de grupos pode ser melhorada com a constituição de grupos mistos, em termos de relacionamento entre os participantes. A evidência disso é dada pela sentença: Estudante 4 "Grupos mais distintos seriam uma forma de todos se sentirem mais cobrados".

Observação 3: Capacidade de reducionismo para formatar o problema foi uma questão relevante e que demandou muito tempo dos estudantes. A solução é um misto de maturidade, conhecimento da organização e ambição. O tempo demandado para identificar uma configuração razoável levou os estudantes a uma sensação de ansiedade e incerteza. Na taxonomia revisada trata-se de uma competência que demanda conhecimentos na dimensão procedural e metacognitiva com decisões grupais, altamente conflitivas. Nesse momento, o estudante se pergunta se a prática vale o esforço e, por outro lado, tem dificuldade de entender a aplicação dessa situação ao ambiente organizacional "real". Como reflexão posterior ao momento em que a disciplina foi ministrada, percebe-se que se torna relevante para que o estudante perceba os benefícios de aprendizagem da disciplina, que o esforço despendido para 
a solução de problemas ocorre na organização em que ele trabalha. Dessa maneira, foi mostrado ao estudante a necessidade de esforço e o desgaste perante situações conflitivas que os aguardam na "vida real". Essa valorização precisa ficar clara para que a percepção de desgaste se transforme em constatação de aprendizagem.

Observação 4: A falta de entendimento ou compromisso sobre a formatação do que deve ser entregue foi relevante e proporcionou percepção de ausência de elementos relevantes na estruturação do projeto. O estabelecimento de critério de atribuição de notas não foi punitivo, mas deveria considerar um mínimo de alinhamento do projeto e relatório final com o padrão definido e apresentado na disciplina. Mais uma vez, a necessidade de feedback se mostra relevante para o entendimento de lacunas e oportunidades de aperfeiçoamento das questões técnicas e também da percepção do professor de que ele pode acreditar que está conduzindo adequadamente, mas não necessariamente os tutorados estão alinhados ao que se propõe.

Observação 5: Os estudantes sentiram falta de material teórico, que deve ser facilitado ou orientado pelo docente e pesquisado por eles. Ainda, reclamaram da falta de percepção da utilidade da teoria, pois sentiram falta de uma abordagem conceitual mais forte e direcionada na disciplina, embora tenha sido fornecida. A evidência da percepção dos estudantes é dada pelos relatos: Estudante 2 - "Ter um pouco mais de teoria sobre o tema de pesquisa. Alteração de grade para que a disciplina fosse mais útil aos alunos". Estudante 6 - "Deveria existir uma maior abordagem teórica para realização da pesquisa". Estudante 7 - "Poderia ter maior acompanhamento teórico dos assuntos relacionados ao problema, por parte do professor". Uma das possíveis causas dessa percepção está relacionada ao grau de heterogeneidade dos grupos em termos de conhecimentos para atender a demanda dos problemas. O grau de heterogeneidade de conhecimentos adquiridos anteriormente demanda que o grupo cubra esse gap. Isso não necessariamente ocorreu em todos os grupos e a zona de conforto de um modelo tradicional, expositivo e pronto para entregar respostas surge como uma resposta imediata.

Observação 6: Adicionalmente, consideraram que o contato com a disciplina ocorreu num momento posterior ao desejável no curso de Contabilidade. Esse questionamento já apareceu na literatura (WHITE III, 2001), sendo de difícil resposta. Isso pode ser constatado pela seguinte evidenciação: Estudantes 1, 3, 4 e 5 - "Deveriam trazer a disciplina para os alunos do 2. ${ }^{\circ}$ ano com a resolução de pequenos casos". Provavelmente a causa desse questionamento estaria ligada ao fato de que o tempo "emocional" disponível de um aluno ao final do curso seja mais complexo e mais premido por demandas externas do que um aluno num estágio anterior, com mais tempo "emocional" interno à instituição de ensino. Também deu para perceber que a aplicação da disciplina em momento anterior proporcionaria ao aluno ferramental de reflexão que ajudaria em outras disciplinas.

\section{CONCLUSÕES}

A principal conclusão sobre a aplicação do método foi que o gerenciamento de algumas etapas, além de um planejamento detalhado e cuidadoso, deve ser direcionado para alguns elementos que demandam ajustes, e forte e contínua revisão por parte do docente condutor do processo. São eles: (i) o leilão de problemas, (ii) o critério de definição do líder, (iii) o processo de "alocação" de participantes, (iv) expansão e redução no tratamento do problema e a (v) formatação do follow-up são ingredientes-chave para o sucesso na disciplina que devem ser definidos a priori e gerenciados durante o curso. Esses elementos permitem que a motivação dos estudantes tenha menor oscilação de interesse e envolvimento.

Muito embora os acadêmicos busquem e se motivem com a prática, não está claro o que ela representa para um grupo que, muitas vezes, é extremamente heterogêneo. Dessa maneira, quanto maior for a possibilidade de haver grupos que tenham alguma semelhança em termos de experiência e conhecimentos, maior a chance de sucesso. Isso pode ser conseguido pela votação 
e eleição dos problemas. Ao trazer um problema de uma empresa a que tenha acesso, o estudante aumenta a chance de sucesso de estudo e proposta de solução, o que seria extremamente complexo sem a disponibilidade da organização.

Como sequência, a repetição das instruções por escrito e oralmente mostra-se fundamental para o entendimento e compreensão. As dimensões da taxonomia revisadas são mais flexíveis e possibilitam a interpolação do processo cognitivo, embora mantenha o design hierárquico da taxonomia original (FERRAZ; BELHOT, 2010). Estrutura que necessariamente não é simétrica no processo educacional, pois o aprendizado não necessariamente ocorre dessa maneira e com essa intensidade. Nesse ponto, o calendário escolar é o limite e tudo acaba sendo feito para viabilizá-lo. Principalmente ao lidar com estudantes que conheçam o ambiente empresarial, existirão atividades competindo com as atividades da disciplina, e compromisso e disciplina serão competências testadas durante o transcorrer do semestre.

Finalmente, o docente não deve se acomodar e deixar a classe se movimentar sem uma liderança clara. Ao contrário, deve perceber se aulas expositivas adicionais são necessárias, se repetições são necessárias, talvez apresentadas de maneiras distintas, se conteúdos devem ser incluídos e aprofundados, e disponibilidade de tempo deve ser viabilizada para atendimento dos grupos. Resumindo, o professor troca, com o PBL, um ambiente relativamente controlado, por um outro, de relativa instabilidade e instigação. Não se trata apenas de uma troca, mas de um processo de desconstrução que vai gerar percepção de ganhos e perdas que devem ser explicados aos participantes. Essa é a riqueza da experiência com uma abordagem que troca o conforto pelo incerto.

\section{REFERÊNCIAS}

ALLEN, D. E.; WHITE III, H. B. Undergraduate group facilitators to meet the challenges of multiple classroom groups. In: DUCH., B. J.; GROH, S. E.; ALLEN, D. E. The power of problem-based learning. Sterling: Stylus, 2001. p. 79-93.

ANDERSON, L. W.; KRATHWOHL, D. R. Taxonomy for learning, teaching, and assessing: a revision of bloom's taxonomy of educational. New York: Addison Wesley, 2000.

ARAÚJO, U. F.; ARANTES, V. A. Comunidade, conhecimento e resolução de problemas: o projeto acadêmico da USP Leste. In: ARAÚJO, U. F.; SASTRE, G. (Org.). Aprendizagem baseada em problemas no ensino superior. São Paulo: Summus, 2009. p. 101-121.

BLOOM, B. et al. Taxonomia de objetivos educacionais: domínio afetivo. Porto Alegre: Globo, 1974.

BLOOM, B. et al. Taxonomia de objetivos educacionais: domínio cognitivo. São Paulo: Pioneira, 1983.

BRANDÃO, C. R.; LESSADRINI, C. D.; LIMA, E. P. Criatividade e novas metodologias. 2. ed. São Paulo: Fundação Petrópolis,1998. v. 4.

DECKER, I. da R.; BOUHUIJS, P. A. J. Aprendizagem baseada e problemas e metodologia da problematização: identificando e analisando continuidades e descontinuidades nos processos de ensino e aprendizagem. In: ARAÚJO, U. F.; SASTRE, G. (Org.). Aprendizagem baseada em problemas no ensino superior. São Paulo: Summus, 2009. p. 177-204. 
DEELMAN, A.; HOEBERIGS, B. A ABP no contexto da Universidade de Maastricht. In: ARAÚJO, U. F.; SASTRE, G. (Org.). Aprendizagem baseada em problemas no ensino superior. São Paulo: Summus, 2009. p. 79-100.

DUCH, B. J. Models for problem-based instruction in undergraduate courses. In: DUCH., B. J.; GROH, S. E.; ALLEN, D. E. The power of problem-based learning. Sterling: Stylus, 2001a. p.39-45.

DUCH, B. J. Writing problems for deeper understanding. In: DUCH., B. J.; GROH, S. E.; ALLEN, D. E. The power of problem-based learning. Sterling: Stylus, 2001b. p.47-53.

DUCH., B. J.; GROH, S. E. Strategies for using groups. In: DUCH., B. J.; GROH, S. E.; ALLEN, D. E. The power of problem-based learning. Sterling: Stylus, 2001a. p. 59-67.

DUCH., B. J.; GROH, S. E. Strategies for using groups. In: DUCH, B. J.; GROH, S. E.; ALLEN, D. E. Assessment in problem-based learning. Sterling: Stylus, 2001b. p. 95-105.

ENEMARK, S.; KJAERSDAM, F. A ABP na teoria e na prática: A experiência de Aalborg na inovação do projeto de ensino universitário. In: ARAÚJO, U. F.; SASTRE, G. (Org.). Aprendizagem baseada em problemas no ensino superior. São Paulo: Summus, 2009. p. 1741.

FERRAZ, A. P. C. M.; BELHOT, R. V. Taxonomia de Bloom: revisão teórica e apresentação das adequações do instrumento para definição de objetivos instrucionais. Gestão da Produção, São Carlos, v. 17, n. 2, p. 421-431, 2010. http://dx.doi.org/10.1590/S0104530X2010000200015.

GALHARDI, A. C.; AZEVEDO, M. M. de. Avaliações de aprendizagem: o uso da taxonomi a de Bloom. In: WORKSHOP DE PÓS-GRADUAÇÃ̃O E PESQUISA DO CENTRO PAULA SOUZA, 8., 2013, São Paulo. Anais..., 2013. Disponível em: $<$ http://www.centropaulasouza.sp.gov.br/pos-graduacao/workshop-de-pos-graduacao-epesquisa/008-workshop-2013/trabalhos/educacao_corporativa/121728_237_247_FINAL.pdf> Acesso em: 07/02/2014.

KOMATSU, R. S.; ZANOLLI, M. B.; LIMA, V. V. Aprendizagem baseada e problemas. In: MARCONDES, E.; GONÇALVES, E. L. (Coord.). Educação médica. São Paulo: Sarvier, 1998. p. 223-237.

MOESBY, E. Perspectiva geral da introdução e implementação de um novo modelo educacional focado na aprendizagem baseada em projetos e problemas. In: ARAÚJO, U. F.; SASTRE, G. (Org.). Aprendizagem baseada em problemas no ensino superior. São Paulo: Summus, 2009. p. 43-78.

NOBRE, J. C. S. et al. Aprendizagem Baseada em Projeto (Project-Based Learning - PBL) aplicada a software embarcado e de tempo real. In: SIMPÓSIO BRASILEIRO DE INFORMÁTICA NA EDUCAÇÃO (SBIE) UNB/UCB, 17., 2006, Brasília. Anais... Brasília, p. 258 a 267.

PINTO, G. R. P. R. ; SANTOS, Celso Alberto Saibel ; PEREIRA, Hernane Borges de Barros . AVPBL: uma ferramenta para auxiliar a sessão tutorial do método de Aprendizagem Baseada 
em Problemas. In: Congresso Nacional de Ambientes Hipermídia para Aprendizagem, 2004. Anais..., Florianópolis, 2004.

RIBEIRO, L. R. de C.; MIZUKAMI, M. das G. N. Uma implementação da aprendizagem baseada em problemas (PBL) na pós-graduação em Engenharia sob a ótica dos alunos. Semina: Ciências Sociais e Humanas, Londrina v. 25, p.89-102, set. 2004.

WHITE III, H.B. Getting started in problem-based learning, In: DUCH., B.J.; GROH, S.E.; ALLEN, D.E. The power of problem-based learning. Sterling, Stylus, 2001, p.69-77. 